\title{
The Temperature Dependence of the Zeta Potential in Porous Media
}

\author{
Luong Duy Thanh ${ }^{*}$ \\ Thuy Loi University, 175 Tay Son, Dong Da, Hanoi, Vietnam \\ Received 03 March 2017 \\ Revised 20 April 2017; Accepted 28 April 2017
}

\begin{abstract}
The measurements of the zeta potential of five consolidated samples including natural and artificial ceramic rocks saturated with $5.0 \times 10^{-3} \mathrm{M} \mathrm{NaCl}$ electrolyte at different temperatures have been reported. The zeta potential obtained in this work is always negative and increases in magnitude with increasing temperature for all samples (an average increase of the zeta potential of $0.4 \mathrm{mV} /{ }^{\circ} \mathrm{C}$ in magnitude). The experimental results are in good agreement with previously published data. The experimental data is then explained by a theoretical model. It is shown that the model is able to reproduce the main trend of the experimental data from our work and from published articles.
\end{abstract}

Keywords: Streaming potential, zeta potential, porous media, rocks, temperature.

\section{Introduction}

Streaming potential plays an important role in geophysical applications. For example, the streaming potential is used to map subsurface flow and detect subsurface flow patterns in oil reservoirs [1]. Streaming potential is also used to monitor subsurface flow in geothermal areas and volcanoes [2, 3]. Monitoring of streaming potential anomalies has been proposed as a means of predicting earthquakes $[4,5]$ and detecting of seepage through water retention structures such as dams, dikes, reservoir floors, and canals [6]. The zeta potential is one of the key parameters in streaming potential. The zeta potential of liquid-rock systems depends on many parameters such as mineral composition of rocks, fluid properties, fluid $\mathrm{pH}$, fluid temperature etc. To quantitatively estimate self-potential anomalies generated by electrokinetics in hydrothermal areas, understanding of the variation of the zeta potential with temperature is very important. The temperature dependence of the zeta potential of porous media has been studied in a number of publications. However, the results are inconsistent and contradictory. For example, some studies have found that the zeta potential increases in magnitude with increasing temperature [e.g., 7-10], while others have found that it decreases in magnitude [e.g., 11-12]. The reason for the inconsistency may be the wide range of materials and electrolyte composition used for zeta potential measurements. The aim of this study is to investigate the

\footnotetext{
* Tel.: 84-936946975.

Email: luongduythanh2003@yahoo.com

https//doi.org/ 10.25073/2588-1124/vnumap.4090
} 
temperature dependence of the zeta potential in five rock samples saturated with a $\mathrm{NaCl}$ electrolyte of $5.0 \times 10^{-3} \mathrm{M}$ over the range of temperature between $6^{\circ} \mathrm{C}$ and $48^{\circ} \mathrm{C}$.

This paper includes five sections. Section 2 describes the theoretical background of streaming potential. Section 3 presents the experimental measurement. Section 4 contains the experimental results and discussion. Conclusions are provided in the final section.

\section{Theoretical background of streaming potential}

\subsection{Physical chemistry of the electric double layer}

Streaming potential is the result of a coupling between fluid flow and electric current flow in a porous medium which is formed by mineral solid grains such as silicates, oxides, carbonates. It is directly related to the existence of an electric double layer (EDL) that exists at the solid-liquid interface. Most substances acquire a surface electric charge when brought into contact with aqueous systems. Although the presence of surface charges is normally accepted without careful consideration of their origin in most streaming potential studies, it is still important to recognize the origin of these charges. Surfaces may become electrically charged by a variety of mechanisms. Some of the main mechanisms responsible for surface charges are (1) surface disassociation, (2) ion adsorption from solution and (3) crystal lattice defects (for more detail, see [13]).

To better understand the origin of surface charge, the physical chemistry at a silica surface in the presence of the aqueous fluids is presented. The reason for considering a silica interface is that the silica is one of the most abundant minerals on the Earth's crust. Therefore it is the main mineral component of rocks. The discussion of the reactions at a silica surface in contact with aqueous fluids has been described by many authors (e.g., $[14,15])$. They state that there are two types of neutral surface group for silica: doubly coordinated siloxal $>\mathrm{Si}_{2} \mathrm{O}^{0}$ and singly coordinated silanol $>\mathrm{SiOH}^{0}$ (where $>$ refer to the mineral lattice and the superscript " $0 "$ means no charge). The siloxal group $\left(>\mathrm{Si}_{2} \mathrm{O}^{0}\right)$ can be considered inert. However, the surface silanol group $\left(>\mathrm{SiOH}^{0}\right)$ can react readily to produce positive surface sites $\left(>\mathrm{SiOH}_{2}{ }^{+}\right.$) at very acid $\mathrm{pH}<\mathrm{pH}_{\mathrm{pzc}}=2-3$ and negative surface sites $\left(>\mathrm{SiO}^{-}\right)$at $\mathrm{pH}>\mathrm{pH}_{\mathrm{pzc}}$ where $\mathrm{pH}_{\mathrm{pzc}}$ is the $\mathrm{pH}$ at the point of zero charge (at which concentration of $>\mathrm{SiOH}_{2}{ }^{+}$is equal to that of $>\mathrm{SiO}^{-}$). The surface mineral reactions at the silanol surfaces in contact with 1:1 electrolyte solutions with the fluid $\mathrm{pH}$ limited to a range of 6-8 are:

To simplify the problem, silica grains in contact with 1:1 electrolyte solutions (i.e., monovalent electrolytes with one cation and one anion) such as $\mathrm{NaCl}$ is considered with the fluid $\mathrm{pH}$ limited to a range of 6-8. The surface mineral reactions at the silanol surface sites are:

for deprotonation of silanol groups

$$
>\mathrm{SiOH}^{0} \Leftrightarrow>\mathrm{SiO}^{-}+\mathrm{H}^{+},
$$

for cation adsorption on silica surfaces

$>\mathrm{SiOH}^{0}+\mathrm{Me}^{+} \Leftrightarrow>\mathrm{SiOMe}^{0}+\mathrm{H}^{+}$,

where $\mathrm{Me}^{+}$stands for monovalent cations in the solutions such as $\mathrm{Na}^{+}$or $\mathrm{K}^{+}$. Note that the positive surface site $\left(>\mathrm{SiOH}_{2}{ }^{+}\right)$does not exist at the silica-electrolyte interface for $\mathrm{pH}>6$. Therefore, three types of sites are present at the silica surfaces, one negative $\left(>\mathrm{SiO}^{-}\right)$and two neutral ones $\left(>\mathrm{SiOH}^{0}\right.$ and $>\mathrm{SiOMe}^{0}$ ).

The law of mass action at equilibrium is used to calculate the equilibrium constants for those reactions in the following manner 
$K_{(-)}=\frac{\Gamma_{S i O^{-}}^{0} \cdot \alpha_{H^{+}}^{0}}{\Gamma_{S i O H}^{0}}$,

and

$$
K_{M e}=\frac{\Gamma_{\text {SiOMe }}^{0} \cdot \alpha_{H^{+}}^{0}}{\Gamma_{\text {SiOH }}^{0} \cdot \alpha_{M e^{+}}^{0}},
$$

where $K_{(-)}$is the disassociation constant for deprotonation of silanol surface sites, $K_{M e}$ is the binding constant for cation adsorption on the silica surfaces, $\Gamma_{i}^{0}$ is the surface site density of surface species $i$ in sites $/ \mathrm{m}^{2}$ and $\alpha_{i}^{0}$ is the activity of an ionic species $i$ at the closest approach of the mineral surface.

The total surface site density $\left(\Gamma_{S}^{0}\right)$ is

$$
\Gamma_{\mathrm{S}}^{0}=\Gamma_{\mathrm{SiOH}}^{0}+\Gamma_{\mathrm{SiO}}^{0}+\Gamma_{\text {SiOMe }}^{0}
$$

Eq. (5) is a conservation equation for mineral surface groups. From Eq. (3) to Eq. (5), the surface site density of sites $\Gamma_{S i O^{-}}^{0}$ and $\Gamma_{\text {Siome }}^{0}$ are obtained. The mineral surface charge density $Q_{S}^{0}$ in $\mathrm{C} / \mathrm{m}^{2}$ can be found by summing the surface densities of charged surface groups (only one charged surface group of $\Gamma_{\mathrm{SiO}^{-}}^{\mathrm{O}}$ in this problem) as

$$
Q_{S}^{0}=-e . \Gamma_{S i O^{-}}^{0}
$$

where $\mathrm{e}$ is the elementary charge.

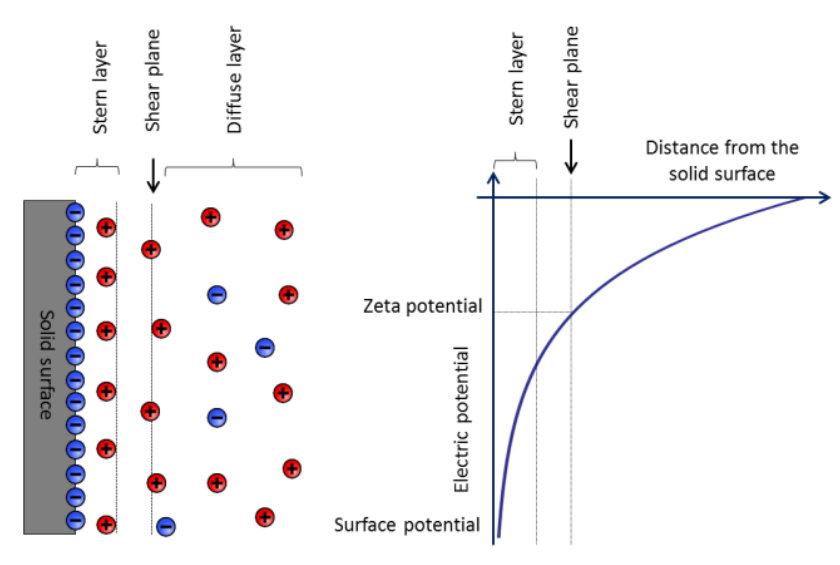

Figure 1. Stern model for the charge and electric potential distribution in the EDL at a solid-liquid interface.

The mineral surface charge repels ions in the electrolyte whose charges have the same sign as the surface charge (called the "coions") and attracts ions whose charges have the opposite sign (called the "counterions" and normally cations) in the vicinity of the electrolyte-silica interface. This leads to the charge distribution known as the electric double layer (EDL) (see Fig. 1). The EDL is made up of the Stern layer, where cations are adsorbed on the surface and are immobile due to the strong electrostatic attraction, and the diffuse layer, where the ions are mobile. The distribution of ions and the electric potential within the diffuse layer is governed by the Poisson-Boltzman (PB) equation which accounts 
for the balance between electrostatic and thermal diffusional forces [16]. The solution to the linear PB equation in one dimension perpendicular to a broad planar interface is well-known and produces an electric potential profile that decays approximately exponentially with distance as shown in Fig. 1. In the bulk liquid, the number of cations and anions is equal so that it is electrically neutral. The closest plane to the solid surface in the diffuse layer at which flow occurs is termed the shear plane or the slipping plane, and the electrical potential at this plane is called the zeta potential $(\zeta)$.

\subsection{Zeta potential}

According to a theoretical model for the zeta potential that has been well described in $[14,15]$, the electrical potential distribution $\varphi$ in the EDL has, approximately, an exponential distribution as follows:

$$
\phi=\phi_{d} \exp \left(-\frac{\chi}{\chi_{d}}\right)
$$

where $\varphi_{d}$ is the Stern potential (V) given by

$$
\phi_{d}=\frac{2 k_{b} T}{3 e} \ln \left\{\frac{\sqrt{8.10^{3} \varepsilon_{o} \varepsilon_{r} k_{b} T N}\left(10^{-p H}+K_{M e} C_{f}\right)}{2 e \Gamma_{S}^{0} K_{(-)}}\left[\frac{C_{f}+10^{-p H}+10^{p H-p K_{w}}}{\sqrt{C_{f}}}\right]\right\}
$$

and $\chi_{d}$ is the Debye length given by

$$
\chi_{d}=\sqrt{\frac{\varepsilon_{o} \varepsilon_{r} k_{b} T}{2000 N e^{2} C_{f}}}
$$

and $\chi$ is the distance from the mineral surface. Eq. (7) is, in fact, the solution of the linearized Poisson-Boltzmann equation describing the electrostatic potential distribution in the electrical double layer and is called the Debye-Huckel approximation. The zeta potential can then be calculated as

$$
\zeta=\phi_{d} \exp \left(-\frac{\chi_{\zeta}}{\chi_{d}}\right)
$$

where $\chi_{\zeta}$ is the shear plane distance (the distance from the mineral surface to the shear plane). There is currently no method to evaluate the shear plane distance. In [15], the shear plane distance was taken as $2.4 \times 10^{-10} \mathrm{~m}$ to compare the theoretical model with experimental datasets of 17 different solidfluid combinations. The results show that the theoretical model fits the experimental data well. Therefore, $\chi_{\zeta}=2.4 \times 10^{-10} \mathrm{~m}$ is also used in this work for modeling.

In Eq. (8) and Eq. (9), $k_{b}$ is the Boltzmann's constant, $\varepsilon_{0}$ is the dielectric permittivity in vacuum, $\varepsilon_{r}$ is the relative permittivity, $T$ is temperature (in $\mathrm{K}$ ), $e$ is the elementary charge, $N$ is the Avogadro's number $C_{f}$ is the electrolyte concentration, $p H$ is the fluid $\mathrm{pH}, K_{\mathrm{Me}}$ is the binding constant for sodium adsorption, $K_{(-)}$is the disassociation constant for dehydrogenization of silanol surface sites, $\Gamma_{S}^{0}$ is the surface site density and $K_{w}$ is the disassociation constant of water.

\subsection{Streaming potential}

In a porous medium the electric current density and the fluid flux are coupled, so that the streaming potential is generated by fluids moving through porous media. The parameter that quantifies this coupling is the streaming potential coefficient (SPC) defined by 


$$
C_{S}=\frac{\Delta V}{\Delta P}=\frac{\varepsilon_{r} \varepsilon_{o} \zeta}{\eta \sigma_{e f f}}
$$

where $\Delta V$ is the streaming potential, $\Delta P$ is the fluid pressure difference, $\varepsilon_{r}$ is the relative permittivity of the fluid, $\varepsilon_{o}$ is the dielectric permittivity in vacuum, $\eta$ is the dynamic viscosity of the fluid, $\sigma_{\text {eff }}$ is the effective conductivity, and $\zeta$ is the zeta potential. The effective conductivity includes the fluid conductivity and the surface conductivity. The SPC can also be written as (see [17] and references therein)

$$
C_{S}=\frac{\varepsilon_{r} \varepsilon_{o} \zeta}{\eta F \sigma_{r}}
$$

where $\sigma_{r}$ is the electrical conductivity of the sample saturated by a fluid with a conductivity of $\sigma_{f}$ and $F$ is the formation factor. The electrical conductivity of the sample can possibly include surface conductivity. If the fluid conductivity is much higher than the surface conductivity, the effective conductivity is approximately equal to the fluid conductivity, $\sigma_{\text {eff }}=F \sigma_{r}=\sigma_{f}$ and the SPC becomes the well-known Helmholtz-Smoluchowski equation:

$$
C_{S}=\frac{\varepsilon_{r} \varepsilon_{o} \zeta}{\eta \sigma_{f}} .
$$

\section{Experiment}

Streaming potential measurements have been performed on five consolidated samples (one Bentheim sandstone sample denoted by BEN7; one artificial ceramic sample denoted by DP217, two Berea sandstone samples denoted by BER502 and BereaUS5 and one Indiana limestone sample denoted by IND01). The mineral composition and micro structure parameters of the samples (porosity, solid density, permeability and formation factor) have been already reported in [18] and re-shown in Table 1. A NaCl electrolyte solution of $5.0 \times 10^{-3} \mathrm{M}$ is used for the measurements.

Table 1. Sample ID, mineral compositions and microstructure parameters of the samples. Symbols $k_{o}$ (in mD), $\phi$ (in $\%$ ),$F$ (no units), $\alpha_{\infty}$ (no units), $\rho_{s}$ (in $\mathrm{kg} / \mathrm{m}^{3}$ ) stand for permeability, porosity, formation factor, tortuosity and solid density of porous media, respectively.

\begin{tabular}{llllllll}
\hline & Sample ID & Mineral compositions & $k_{o}$ & $\phi$ & $F$ & $\alpha_{\infty}$ & $\rho_{s}$ \\
\hline 1 & BEN7 & Mostly Silica & 1438 & 22.2 & 12.6 & 2.8 & 2647 \\
2 & DP217 & Alumina and fused silica & 370 & 45.4 & 4.5 & 2.0 & 3652 \\
& & & & & & \\
3 & BER502 & Silica, Alumina, Ferric Oxide & 182 & 22.5 & 13.5 & 3.0 & 2723 \\
4 & BERUS5 & - & 310 & 20.1 & 14.5 & 2.9 & 2514 \\
5 & IND01 & Mostly Calcite, silica, Alumina, Magnesium & 120 & 14.5 & 19.0 & 2.8 & 2602 \\
\hline
\end{tabular}

The experimental setup for the streaming potential is the same as reported in [17]. The core holder contains a cylindrical sample of $55 \mathrm{~mm}$ in length and $25 \mathrm{~mm}$ in diameter. Each sample is surrounded by a $4 \mathrm{~mm}$ thick silicone sleeve inside a conical stainless steel cell and inserted into a stainless steel holder to prevent flow a long the interface of the sample. To measure the streaming potential as a function of temperature, the core holder and the bottle containing the electrolyte are immersed into a thermally stabilized water bath (Thermo Fisher Scientific SC150 and A25) as shown in Fig. 2. Temperatures used in our measurements are $6^{\circ} \mathrm{C}, 11^{\circ} \mathrm{C}, 16^{\circ} \mathrm{C}, 21^{\circ} \mathrm{C}, 26^{\circ} \mathrm{C}, 31^{\circ} \mathrm{C}, 36^{\circ} \mathrm{C}, 41^{\circ} \mathrm{C}$ and $46^{\circ} \mathrm{C}$, 
respectively. It should be noted that the model presented in section 2 is only valid in the range $0^{\circ} \mathrm{C}$ $100^{\circ} \mathrm{C}[15]$.

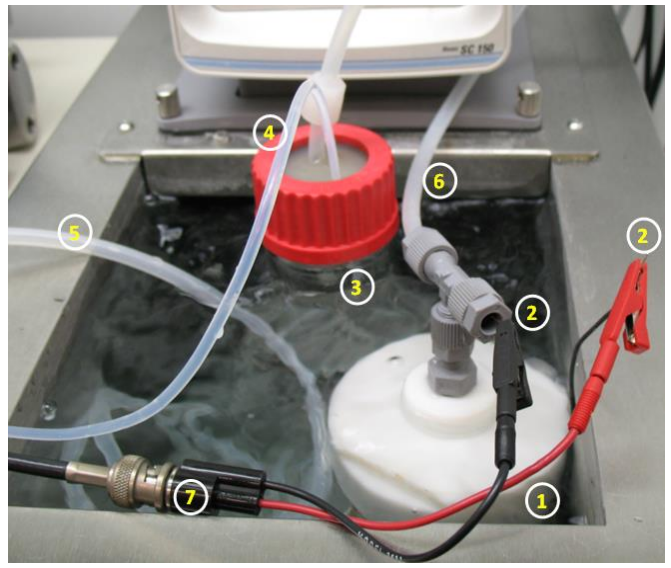

Figure 2. The main part of the setup for streaming potential measurements as a function of temperature. 1, Core holder; 2, Ag/AgCl electrodes; 3, Solution container; 4, Tubing used to pump the solution from the container; 5,

Tubing connecting the pump outlet and the core holder inlet; 6 , Tubing for recirculation; 7 , Shield cable for electrical potential measurements

The way used to collect the SPC is similar to that described in [17, 19]. Firstly, streaming potential across the sample $(\Delta \mathrm{V})$ is measured as a function of applied pressure difference $(\Delta \mathrm{P})$. The SPC is then obtained as the slope of the straight line as shown in [17] (see Fig. 6 in [17]). Three measurements are performed to find the average value of the SPC. It is found that the SPC is negative regardless of temperature for all samples.

To check how the SPC varies over time at a given temperature, the SPC is measured as a function of time at room temperature as shown in Fig. 3 by continuously pumping the fluid through the sample and measuring the SPC after every a specific amount of time. Fig. 3 shows that initially the SPC decreases drastically over time which could be due to the change of conductivity and $\mathrm{pH}$ (CO2 uptake or electrode polarization drift or mineral decay from samples) and after about 50h, the SPC gets relatively stable. Therefore, the SPC as a function of temperature is collected after $50 \mathrm{~h}$.

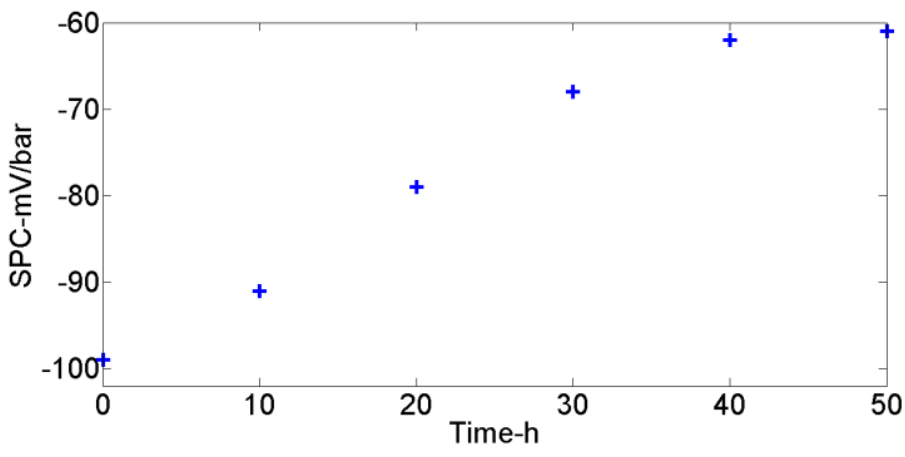

Figure 3. The streaming potential coefficient as a function of time at room temperature for the sample of BEN7

To investigate how long it takes to get thermal equilibrium for the samples inside the core holder. We fix a sensor probe tip of the digital temperature meter (Omega DP460) on the outlet surface of the sample and find that the time period to get thermal equilibrium is around 45 minutes (temperature read 
out by the digital meter becomes the same as that read by the water bath when continuously pumping liquid through the sample). Therefore, we take 45 minutes as a time sampling (time between two consecutive measurements).

\section{Results and discussion}

From the measured values of the SPC at different temperatures, the relation between the SPC and temperature is shown in Fig. 4. It is seen that the magnitude of the SPC increases with increasing temperatures for all samples. This observation is in good agreement with the results reported in literature [e.g., 20]. Pengra et al. [20] carried out measurements for Fontainebleau sandstone, Berea sandstone and Indiana Limestone saturated with $0.1 \mathrm{M} \mathrm{NaCl}$ electrolyte (Fig. 4). The SPC obtained in [20] is smaller than our data for the same type of rocks because of the higher electrolyte concentration $(0.1 \mathrm{M} \mathrm{NaCl})$. The measured electrical conductivities of all samples against temperature are shown in Fig. 5. These data show that the electrical conductivity of the saturated sample increases with increasing temperature and that is consistent with that obtained in [12]

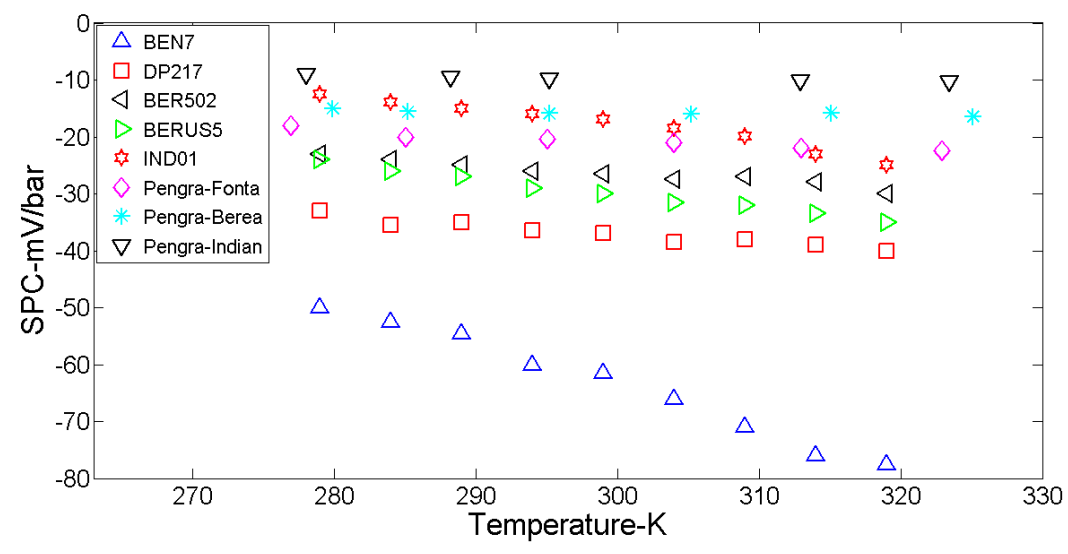

Figure 4. Streaming potential coefficient as a function of temperature. Experimenatal data from [20]: PengraFonta for Fontainebleau sandstone; Pengra-Berea for Berea sandstone; Pengra-Indian for Indiana Limestone.

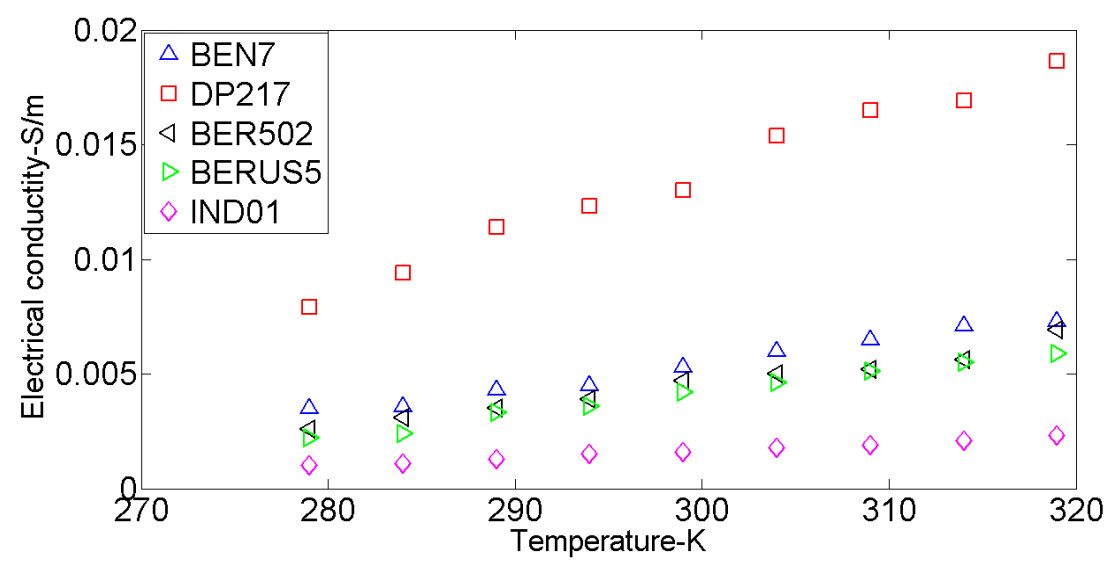

Figure 5. Electrical conductivity of the saturated samples as a function of temperature. 
To take into account the variation of the relative electric permittivity with temperature, the empirical equation mentioned in [15] is used

$$
\varepsilon_{r}\left(T, C_{f}\right)=a_{0}+a_{1} T+a_{2} T^{2}+a_{3} T^{3}+c_{1} C_{f}+c_{2} C_{f}^{2}+c_{3} C_{f}^{3},
$$

where $a_{0}=295.68, a_{1}=-1.2283 \mathrm{~K}^{-1}, a_{2}=2.0941 \times 10^{-3} \mathrm{~K}^{-2}, a_{3}=-1.41 \times 10^{-6} \mathrm{~K}^{-3}, c_{1}=-13 \mathrm{Lmol}^{-1}, c_{2}=$ $1.065\left(\mathrm{Lmol}^{-1}\right)^{2}, c_{3}=-0.03006\left(\mathrm{Lmol}^{-1}\right)^{3}, \mathrm{~T}$ is in Kelvin, the equation is valid in the range from $273 \mathrm{~K}$ to $373 \mathrm{~K}$, and $C_{\mathrm{f}}$ is the electrolyte concentration in $\mathrm{mol} / \mathrm{L}$. A plot of the temperature dependence of the relative electric permittivity is shown in Fig. 6 for the $5.0 \times 10^{-3} \mathrm{M} \mathrm{NaCl}$ electrolyte.

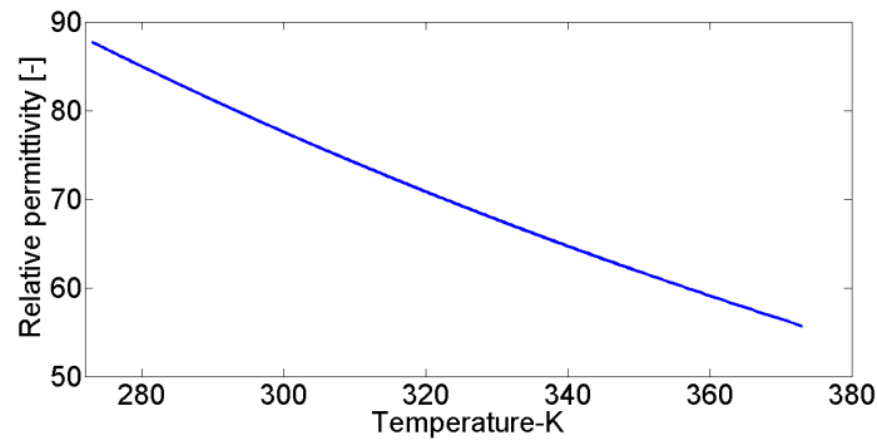

Figure 6. Relative permittivity as a function of temperature.

The variation of the viscosity of the fluid against temperature presented is given by [21]

$$
\eta\left(T, C_{f}\right)=e_{1}+e_{2} \exp \left(\alpha_{1} T\right)+e_{3} \exp \left(\alpha_{2} C_{f}\right)+e_{4} \exp \left(\alpha_{3} T+\alpha_{4} C_{f}\right) \text {, }
$$

where $e_{1}=4.95166 \times 10^{-5} \mathrm{~Pa} . \mathrm{s}, e_{2}=6.034658 \times 10^{-4} \mathrm{~Pa} . \mathrm{s}, e_{3}=9.703832 \times 10^{-4} \mathrm{~Pa} . \mathrm{s}, e_{4}=1.025107 \times 10^{-}$ ${ }^{4} \mathrm{~Pa} . \mathrm{s}, \alpha_{1}=-0.06653081 /{ }^{\circ} \mathrm{C}, \alpha_{2}=-0.1447269 / \mathrm{molar}, \alpha_{3}=-0.02062455 /{ }^{\circ} \mathrm{C}, \alpha_{4}=-0.1301095 / \mathrm{molar}, \mathrm{T}$ is in ${ }^{\circ} \mathrm{C}$. Fig. 7 shows the temperature dependence of the viscosity of the electrolyte.

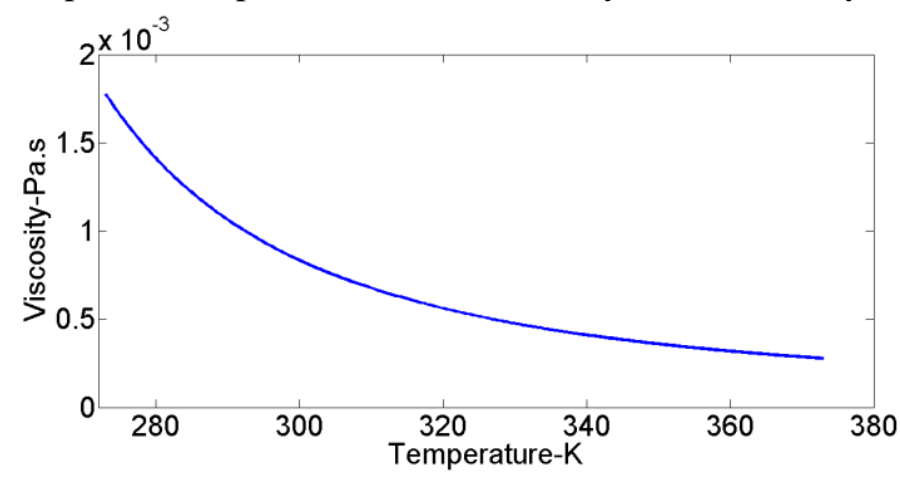

Figure 7. Viscosity as a function of temperature.

The zeta potential is then obtained for all samples at different temperatures using the data recorded in Fig. 4, Fig. 5, Fig. 6, Fig. 7 and Eq. (12) (see Fig. 8). It is seen that the zeta potential in magnitude increases with increasing temperature for all samples. Our observation is in good agreement with experimental data available in literature [e.g., 7-9] as shown in Fig. 8. By linearly fitting experimental data, an increase of the zeta potential is found to be $-0.82 \mathrm{mV} /{ }^{\circ} \mathrm{C},-0.25 \mathrm{mV} /{ }^{\circ} \mathrm{C},-0.24 \mathrm{mV} /{ }^{\circ} \mathrm{C},-0.38$ $\mathrm{mV} /{ }^{\circ} \mathrm{C}$ and $-0.26 \mathrm{mV} /{ }^{\circ} \mathrm{C}$ for the samples of BEN7, DP217, BER502, BERUS5 and IND01, 
respectively (an average increase of the zeta potential of $-0.4 \mathrm{mV} /{ }^{\circ} \mathrm{C}$ ). The obtained values are in the same range as those reported in $[7]\left(-1.0 \mathrm{mV} /{ }^{\circ} \mathrm{C}\right)$ and in $[8]\left(-0.33 \mathrm{mV} /{ }^{\circ} \mathrm{C}\right)$.

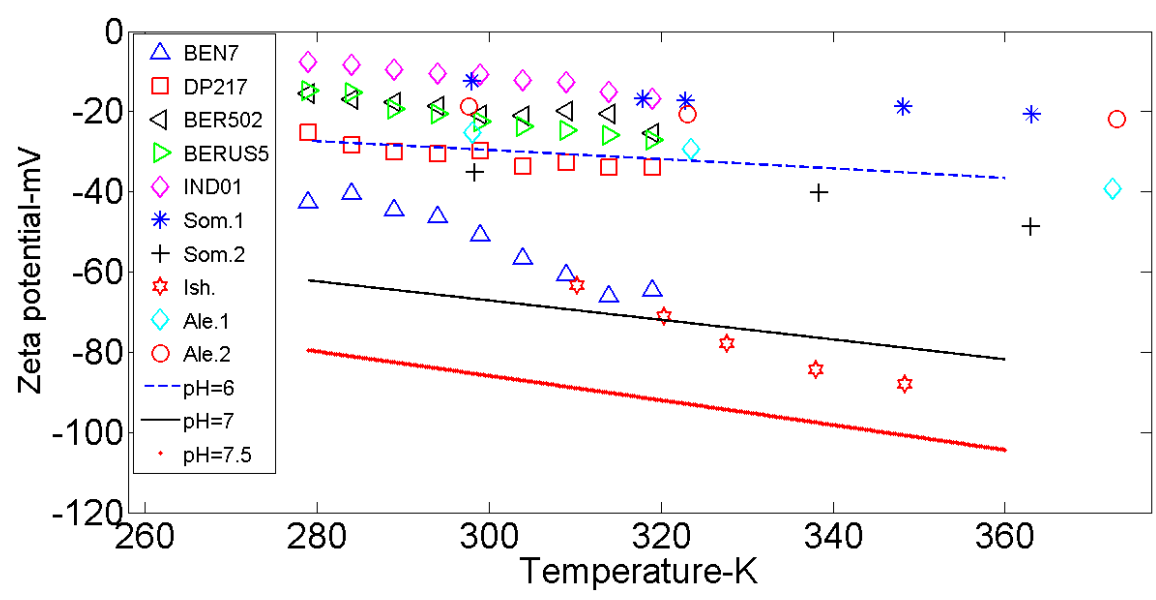

Figure 8. Zeta potential as a function of temperature from our experimental data, from published experimental data (Som.1, Som.2, Ishi., Ale.1 and Ale.2) and from the model (lines). Published data sets: Som.1 and Som.2 from [7] for Hematite and $\mathrm{Al}_{2} \mathrm{O}_{3}$ saturated by $10^{-3} \mathrm{M} \mathrm{HNO}_{3}$; Ishi. from [8] for Quartz saturated by $10^{-3} \mathrm{M} \mathrm{HNO}_{3}$; Ale.1 and Ale.2 from [9] for $\mathrm{SiO}_{2}$ and $\mathrm{Al}_{2} \mathrm{O}_{3}$ saturated by $10^{-3} \mathrm{M} \mathrm{NaCl}$.

To explain the behavior in Fig. 8, we use equations from eq. (7) to eq. (10) to calculate the zeta potential using rock-fluid interface parameters already provided in [15] for silica-based samples. The value of the disassociation constant, $\mathrm{K}_{(-)}$, for dehydrogenization of silanol surface sites is taken as $10^{-7.1}$. The binding constant for cation adsorption, $\mathrm{K}_{\mathrm{Me}}$, is taken as $10^{-7.5}$. The shear plane distance, $\chi_{\zeta}$, is taken as $2.4 \times 10^{-10} \mathrm{~m}$. The surface site density, $\Gamma_{s}^{0}$, is taken as $2 \times 10^{18} \mathrm{site} / \mathrm{m}^{2}$. Electrolyte concentration, $C_{f}$, is taken as $5 \times 10^{-3} \mathrm{M}$. The disassociation constant of water, $\mathrm{K}_{\mathrm{w}}$, varies with temperature and is approximately in the range of $0^{\circ} \mathrm{C}$ to $100^{\circ} \mathrm{C}$ as follows [22]

$$
\mathrm{K}_{\mathrm{w}}=6.9978 \times 10^{-16}+5.0178 \times 10^{-16} T-2.4434 \times 10^{-17} T^{2}+7.1948 \times 10^{-19} T^{3} \text {, }
$$

where $T$ is in ${ }^{\circ} \mathrm{C}$.

Indeed, the fluid $\mathrm{pH}$ is also defined by the reaction of water with carbon dioxide from the air which generates bicarbonate $\left(\mathrm{HCO}_{3}\right)$ and hydrogen ions $\left(\mathrm{H}^{+}\right)$[15]. This leads to that water exposed to air is slightly acidic. The $\mathrm{pH}$ is needed to calculate the concentrations of hydrogen ions $\left(10^{-p H}\right)$ and hydroxyl ions $\left(10^{\left(p H-p K_{W}\right)}\right)$ in the fluid. The $\mathrm{pH}$ value required to model is directly measured by a $\mathrm{pH}$ meter and it ranges between 6 and 7.5 in this work. Therefore, three values of $\mathrm{pH}=6,7$ and 7.5 are used for model. The model prediction is in good agreement with our data and published experimental data [7-9] (lines in Fig. 8). It is seen that the zeta potential versus temperature is also very sensitive to fluid $\mathrm{pH}$ and $\mathrm{pH}=6$ gives better fit than the others. Both the experimental and theoretical results show that the SPC increases with increasing temperature.

\section{Conclusions}

The temperature dependence of the zeta potential has been deduced from the streaming potential measurements for 5 consolidated samples saturated with $5.0 \times 10^{-3} \mathrm{M} \mathrm{NaCl}$ electrolyte. The experimental results show that the zeta potential increases in magnitude with increasing temperature for all samples (an average increase of the zeta potential in magnitude of $0.4 \mathrm{mV} /{ }^{\circ} \mathrm{C}$ ) and that is 
consistent with previously published data. Even though others have found that it decreases in magnitude. The reason for the inconsistency may be the wide range of mineral composition of rocks and electrolytes for which the temperature dependence of the zeta potential was measured. The experimental data is then analyzed by the theoretical model in which the variation of the Stern potential, the Debye length and the disassociation constant of water with temperature is taken into account. It is shown that the model is able to reproduce the main trend of the experimental data from our work and from published articles. The results also show that the model is very sensitive to the $\mathrm{pH}$ of the fluid. Therefore, the fluid $\mathrm{pH}$ needs to be carefully taken into account during measurements.

\section{Acknowledgments}

The author would like to thank Dr. Rudolf Sprik at the Van der Waals-Zeeman Institute/Institute of Physics, University of Amsterdam for his great support and helpful comments. This research is funded by Vietnam National Foundation for Science and Technology Development (NAFOSTED) under grant number 103.99-2016.29.

\section{References}

[1] B. Wurmstich, F. D. Morgan, Geophysics 59 (1994) 46-56.

[2] R. F. Corwin, D. B. Hoovert, Geophysics 44 (1979) 226-245.

[3] F. D. Morgan, E. R. Williams, T. R. Madden, Journal of Geophysical Research 94 (1989) 12.449-12.461.

[4] H. Mizutani, T. Ishido, T. Yokokura, S. Ohnishi, Geophys. Res. Lett. 3 (1976).

[5] M. Trique, P. Richon, F. Perrier, J. P. Avouac, J. C. Sabroux, Nature (1999) 137-141.

[6] A. A. Ogilvy, M. A. Ayed, V. A. Bogoslovsky, Geophysical Prospecting 17 (1969) 36-62.

[7] P. Somasundaran and R. D. Kulkarni, Journal of Colloid and Interface Science 45 (1973) 591-600.

[8] T. Ishido and H.Mizutani, Journal of Geophysical Research 86(1981) 1763-1775.

[9] Y. V. Alekhin, M.P. Sidorova, L.I. Ivanova, and L. Z.Lakshtanov, Kolloidn. Zh. 46(1984), 1195-1198.

[10] Philip M. Reppert, Ph.D. thesis, Massachusetts Institute of Technology, USA (2000).

[11] D. E. Dunstan, Journal of Colloid and Interface Science 166(1994) 472-475.

[12] J. Vinogradov and M. D. Jackson, Geophysical Research Letters 42 (2015).

[13] R. J. Hunter, Zeta Potential in Colloid Science, Academic, New York, 1981.

[14] A. Revil and P. W. J. Glover, Physical Review B 55(1997) 1757-1773.

[15] Glover P.W.J., Walker E., M. Jackson, Geophysics 77 (2012), D17-D43.

[16] H. M Jacob and B. Subirm, Electrokinetic and Colloid Transport Phenomena, Wiley-Interscience, 2006.

[17] Thanh, L. D. and Sprik, R. (2016), Geophysical Prospecting, 64: 714-725.

[18] D. T. Luong and R. Sprik (2014), International Journal of Geophysics, Article ID 471819.

[19] D. T. Luong and R. Sprik (2016), Geophysics, 81 (4): D303-D314.

[20] Pengra, D. B., S. Xi Li, and P. Wong (1999), Determination of rock properties by low-frequency AC electrokinetics, J. Geophys. Res., 104(B12), 29485-29508.

[21] Phillips S.L., Ozbek H., R. Otto, 6th International CODATA Conference (1978)

[22] David R. Lide. CRC Handbook of Chemistry and Physics. CRC Press, 2004. 